so poor. I have seen several cases where after an ideal extraction the sight was very bad, although the fundus was quite normal.

April 6, 1933. The patient attended for re-examination. Most of the blood has now been absorbed, but each pouch still contains a little. The fundus can be clearly seen and the corrected vision is $6 / 18$.

\title{
DIABETIC CATARACT
}

BY

\author{
LT.-Col. E. O'G. KiRWAN, I.M.S. \\ PROFESSOR OF OPHTHALMOLOGY, MEDICAL COLLEGE HOSPITAL, \\ CALCUTTA
}

In Bengal, diabetes is a very common disease and usually develops in early middle life, but most of the cases that one sees are in the fifth and sixth decades. The disease is much more common in men than in women, and principally affects the educated middle class, which includes such people as lawyers, doctors, landowners, business men, clerks, and so on. It is not often seen among the peasants who have to work hard and take a lot of exercise. Women seldom suffer from diabetes. The disease cannot be said to be due to an excessive amount of carbohydrate food, as women eat as much carbohydrate as men. Diabetes in Bengal is usually associated with over-eating, lack of exercise, and oral sepsis, which result in dyspepsia, and there is usually mental worry. Large numbers of Bengalis are chronic dyspeptics, so that their food is not properly assimilated; they take very little exercise, and spend daily long hours at their business or profession, which must eventually result in mental strain. In contrast, their women folk have plenty of time to take their food, and in one way or another, take a considerable amount of exercise; but women who undertake the duties of men, such as looking after a business or doing professional work, are not exempt from diabetes, as their physical and mental condition simulate those of men. Heredity is an important factor in diabetes in Bengal, and frequently one comes across the disease in several members of the same family.

The ocular complications of diabetes are many, such as changes in refraction, paralysis of muscles, amblyopia, iritis, retrobulbar neuritis, retinitis, retinal lipaemia, haemorrhages, cataract, glaucoma and xanthelasma. In Bengal, far and away the commonest ocular complication is retinal haemorrhages.

As diabetes mellitus is probably more prevalent in Bengal than in any other part of the world, one would expect to see a large number 
of cases of diabetic cataract. Typical senile cataract is very frequently associated in elderly people with diabetes, and my experience coincides with that of Foster Moore, that the incidence of cataract in diabetics is greater than in non-diabetics of the same age, and as a result of diabetes, lens changes appear at a relatively earlier age, and tend to mature more rapidly. Maynard, in his "Manual of Ophthalmic Practice," after a long experience of ophthalmology in Bengal, considered the occurrence of cataract in middle-aged diabetics purely accidental as a rule, and that diabetes may influence the progress of senile cataract, but he did not believe it to be a cause of senile cataract, and he considered that there was no proof that in Bengal there is any connection between diabetes and senile cataract. It is now an undoubted fact that diabetes is very often associated with a typical senile cataract, but can hardly be looked upon in these cases as a definite cause of cataract.

In early life there is an undoubted association of diabetes with cataract, it presents definite morphological features, and it occurs in young adults and children, and is really the only true form of diabetic cataract. This cataract occurs when the disease is severe, and develops rapidly in both eyes. The opacities occur first in the posterior cortical layer and extend into the anterior cortical layer, and are situated immediately beneath the capsules. Fluid vacuoles can be seen in small or large numbers just below the anterior or the posterior capsules. The vacuoles are supposed to be due to the altered equilibrium of the aqueous, resulting in an increased inflow of fluid into the lens which results in the formation of opacities in the anterior and posterior cortical layers.

Four cases of diabetic cataract with definite morphological features have recently been seen by me in the Eye Infirmary, Medical College, Calcutta.

\section{Case No. I}

R.K.V., male, Bengali Hindu, aged 26 years. His past history showed dietary excesses, dyspepsia, and constipation. His family history showed no history of diabetes. Sugar was first discovered in the urine three years ago, in 1929. His symptoms were defective vision, polyuria, thirst and emaciation. At the time of admittance into hospital on June 9, 1932, he was thin and emaciated, and was totally blind from cataract. The blood pressure was $130 / 90 \mathrm{~mm}$. Hg. The Wassermann test was negative. The blood sugar (fasting) was 0.418 per cent. His urine showed a specific gravity of 1,042, sugar 8.5 per cent., albumen a trace, acetone in large quantities, and a small amount of diacetic acid. The patient was put on a diet with a food value of C.130, P.100, F.160, with the caloric value of about 2,500. The daily excretion of sugar varied between 80 and 130 grammes. The diet was then reduced to C.60, 

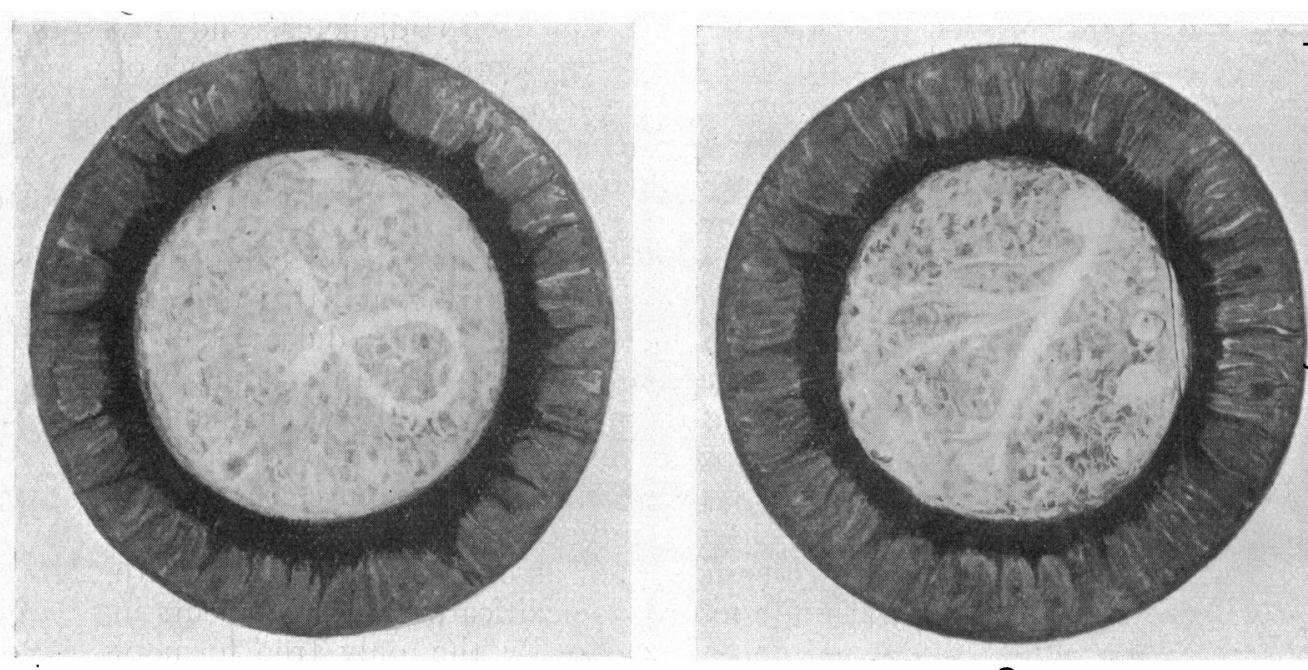

Fig. 1.

P.80, F.140, with a caloric value of about 2,000, and insulin treatment started. For a period of about two to three weeks there was very little response to treatment, except that the patient began to feel stronger and gain in weight. The improvement then became steady, and on August 4, 1932, his blood sugar came down to 0.16 per cent., and the urine was sugar free.

The vision in both eyes was perception of light only. Examination with the corneal microscope showed dense white linear opacities with multiple small vacuoles in between. These vacuoles resembled sago grains, were 1-2 $\mathrm{mm}$. in diameter, were situated in the anterior sub-capsular layer in the same plane, and showed no tendency to fuse together. The anterior capsules were normal. Owing to the density of the opacities, only the anterior cortical layers could be seen, see Fig. 1.

Both eyes were operated upon, and very little difficulty was experienced in the extraction of the cataracts; the lenses were thin with a ring of pigment from the posterior surface of the iris on the periphery. When last seen on December 15, 1932, the vision in both eyes corrected with glasses was $6 / 6$.

\section{Case No. 2}

N. B. K., male, Mohammedan, aged 28 years. His past history showed that he had been suffering from diabetes for the past two years with frequent micturition, thirst, hunger, and gradual wasting. There was total loss of vision in both eyes for about one year. The 
R.E.

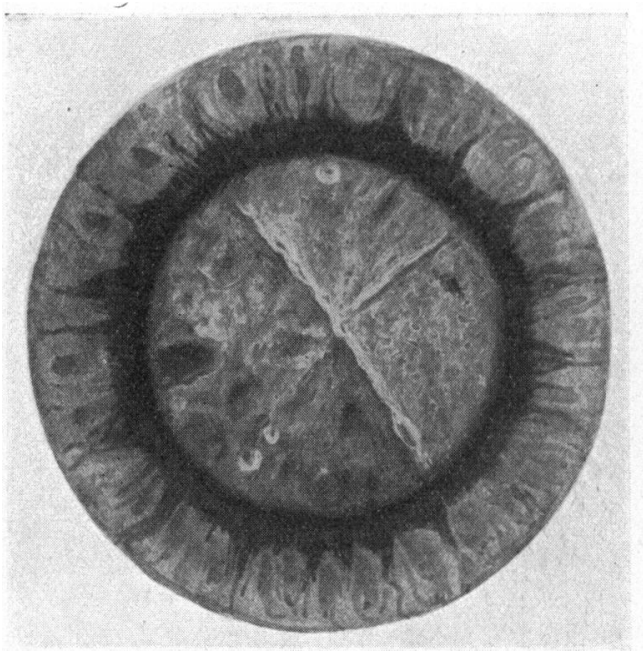

L.E.

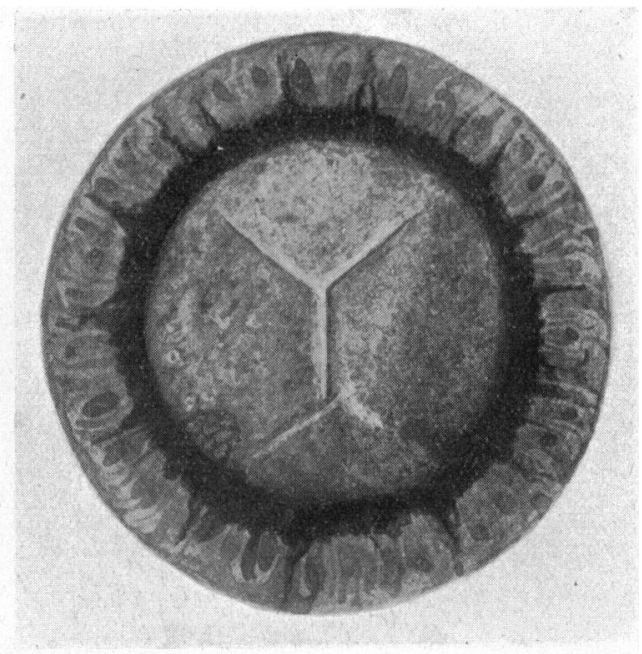

Fig. 2.

left eye was first affected. He stated that he could see very well with both eyes three years ago. No family history of diabetes. At the time of his admittance into the Eye Infirmary, Calcutta, on October 20,1932 , the urine sugar on ordinary diet was $4^{*} 6$ per cent., the blood sugar on ordinary diet was 0.45 per cent. After a course of insulin treatment and restricted diet, the urine became sugar free and the blood sugar fell to 0.20 per cent.

The vision in both eyes was perception of light only. Examination with the corneal microscope showed numerous dense cloudy opacities with clefts between the fibres and sub-capsular vacuoles. The latter were not numerous. The lens sutures in both eyes were very evident, see Fig. 2.

Both eyes were operated upon and the cataracts removed without any difficulty. In both eyes there was a large thin nucleus with evidence of a chronic iritis. Convalescence was uneventful, and when last seen on December 30,1932, the vision in both eyes without needling was $6 / 9$.

\section{Case No. 3}

J. N. M., male, Bengali Hindu, aged 30 years. His past history showed that he had been suffering from diabetes for the past three years. He complained of great thirst and frequency of micturition. His vision had been failing for about two years, the right eye was first affected. No family history of diabetes. At the time of his admittance into hospital on December 8,1932 , the urine sugar on ordinary 

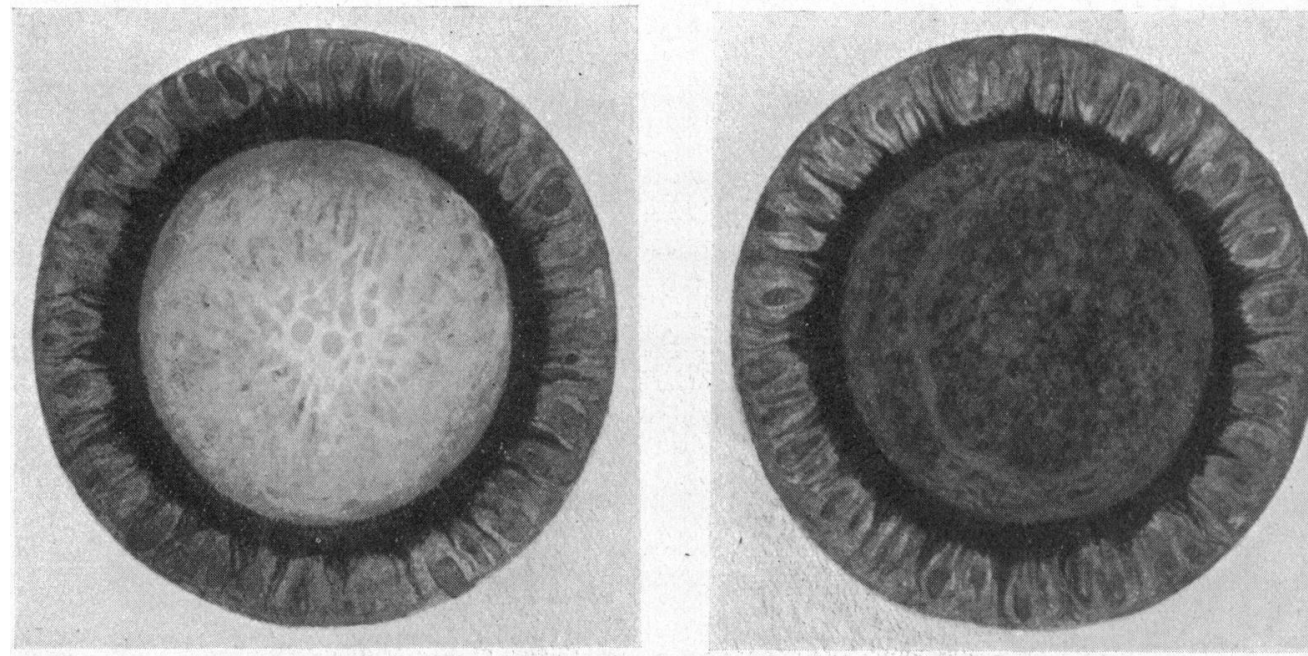

Diabetic cataract, both eyes, with involvement of anterior sub-capsular cortex in the Right, and posterior sub-capsular cortex in the Left.

diet was 4 per cent., the blood sugar on ordinary diet was 0.25 per cent. After gradual restricted diet and insulin treatment the urine quickly became sugar free and the blood sugar dropped to normal. The vision in the right eye was perception of light only and in the left eye 6/36. Examination with the corneal microscope showed dense white linear opacities in the anterior cortical layer and subcapsular vacuoles in the right lens. The left lens showed numerous linear opacities which were iridescent in the posterior cortical layer, and also the presence of small vacuoles immediately below the posterior capsule; the anterior cortex was not involved.

The right eye was operated upon on December 21, 1932, and the cataract removed without difficulty; there was a large nucleus with very little soft cortical matter. When last seen on January 15, 1933 , the vision was $6 / 6$.

\section{Case No. 4}

S. K. B., male, Bengali Hindu, aged 22 years. Was admitted into hospital on October 25, 1932, suffering from polyuria, great thirst, excessive appetite, general weakness, pains in the legs, and dim vision in both eyes. His past history showed that he had been suffering from diabetes for about two years. At the time of admittance into hospital, he was passing 90 grams. of sugar in the urine in 24 hours. The blood sugar was 0.38 per cent. which on treatment fell to 0.15 per cent. The patient died of acute miliary tuberculosis on December 24, 1932. 
Ophthalmic examination-Vision $6 / 60$ both eyes. With the corneal microscope the anterior cortical layer of the lenses was normal. Small linear opacities with very small vacuoles varying from 0.05 to $0.10 \mathrm{~mm}$. in size were seen in the posterior subcapsular layer of the lenses.

It is of interest that the operations for the removal of the cataract in these cases were not difficult, the lenses separated very easily and there was no trouble with haemorrhage.

I have seen a number of cases of severe diabetes in young children with high urine and blood sugars whose vision was normal, but the duration of the disease had not been long enough to cause lens changes, and when they received appropriate treatment to bring down the sugar percentage to nearly normal in the blood, lens opacities did not occur.

Before the removal of senile cataracts in diabetes, one must be very careful to bring down the blood sugar to nearly normal or normal before operation. Haemorrhage is usually troublesome and often leads to a dense after cataract.

At the time of operation, it is always wise to irrigate all soft lens matter from the anterior chamber and then perform a small buttonhole iridectomy in preference to a complete iridectomy. The less the iris is injured, the less the haemorrhage and the less chance of a dense posterior capsule afterwards.

\title{
REFERENCES
}

Foster Moore.-Medical Ophthalmology, 1925.

Maynard.-Manual of Ophthalmic Practice, 1920.

\section{MICROPHTHALMOS WITH CONGENITAL DEFECT OF THE LACRIMAL APPARATUS}

\author{
BY \\ S. Silverman, B.Sc., M.B.Ch.B. \\ CLINICAL ASSISTANT, QUEEN'S HOSPITAL, BIRMINGHAM
}

THE following case of a congenital abnormality of the left eye and lacrimal apparatus in a premature female infant which survived for three and a half months is sufficiently rare to justify record and description.

The mother, aged 35 years, has two childen, a boy, aged 14 years and a girl, aged 10 years. Her Wassermann reaction was negative. The father is 43 years of age. No congenital abnormalities are traceable in the parents, children or family, though the 